\title{
Comparative cytogenetics of two species of genus Scobinancistrus (Siluriformes, Loricariidae, Ancistrini) from the Xingu River, Brazil
}

\author{
Adauto Lima Cardoso', Karline Alves Holanda Sales', Cleusa Yoshiko Nagamachi', \\ Julio Cesar Pieczarka', Renata Coelho Rodrigues Noronha' \\ I Laboratório de Citogenética, Instituto de Ciências Biológicas, Universidade Federal do Pará - Campus do \\ Guamá (Belém, PA, Brazil) \\ Corresponding author: Renata Coelho Rodrigues Noronha (renatarcrn@gmail.com)
}

Academic editor: V. Gokhman | Received 15 October 2012 | Accepted 19 February 2013 | Published 18 March 2013

Citation: Cardoso AL, Sales KAH, Nagamachi CY, Pieczarka JC, Noronha RCR (2013) Comparative cytogenetics of two species of genus Scobinancistrus (Siluriformes, Loricariidae, Ancistrini) from the Xingu River, Brazil. Comparative Cytogenetics 7(1): 43-41. doi: 10.3897/CompCytogen.v7i1.4128

\begin{abstract}
The family Loricariidae encompasses approximately 800 species distributed in six subfamilies. The subfamily Hypostominae consists of five tribes; of them, the tribe Ancistrini is relatively diverse, but it is not well known from the cytogenetic point of view. Genus Scobinancistrus Isbrücker et Nijssen, 1989, which is part of the tribe Ancistrini, has two species that occur in sympatry in the Xingu River, Brazil. In this work, we performed the first karyotypic characterizations of these two species and sought to identify the processes involved in their karyotypic evolution. Chromosomal preparations were subjected to Giemsa staining, silver nitrate impregnation, C-banding, $\mathrm{CMA}_{3}$ staining, DAPI staining, and FISH (fluorescence in situ hybridization) with $18 \mathrm{~S} \mathrm{rDNA}$ and telomeric probes. We found that $S$. aureatus Burgess, 1994 and S. pariolispos Isbrücker et Nijssen, 1989 shared the diploid number, $2 \mathrm{n}=52$, but differed in their karyotypic formulae (KFs), distribution of constitutive heterochromatin $(\mathrm{CH})$, and the localizations of their nucleolus organizer regions (NORs), which were found on the interstitial and distal regions of the long arm of chromosome pair 3 in $S$. aureatus and S. pariolispos respectively. We suggest that these interspecific variations may have arisen via paracentric inversion or transposition of the NOR. The karyotypic differences found between these two Scobinancistrus species can be used to identify them taxonomically, and may have functioned as a mechanism of post-zygotic reproductive isolation during the speciation process.
\end{abstract}

\section{Keywords}

Karyotypic divergence, chromosome rearrangements, sympatry

Copyright Adauto Lima Cardoso et al. This is an open access article distributed under the terms of the Creative Commons Attribution License 3.0 (CC-BY), which permits unrestricted use, distribution, and reproduction in any medium, provided the original author and source are credited. 


\section{Introduction}

The fishes of the family Loricariidae are an important component of the ichthyofauna in the Neotropical region, where they are widely distributed and occupy a great variety of freshwater environments (Isbrücker 1980). The 800 known species are organized into six subfamilies: Hypoptopomatinae, Hypostominae, Lithogeninae, Loricariinae, Neoplecostominae and Delturinae (Armbruster 2004, Reis et al. 2006). The subfamily Hypostominae encompasses five tribes, Corymbophanini, Rhinelepini, Hypostomini, Ancistrini and Pterygoplichthyini, with the latter two forming the most derived clade (Armbruster 2004). The Ancistrini include numerous species with several yet-unsolved taxonomic problems, making it difficult to recognise them (Alves et al. 2003).

Cytogenetic information is incipient, given the great diversity of Ancistrini species, and has been efficient in distinguishing species of this tribe (Alves et al. 2003, Souza et al. 2009). It is therefore necessary to increase the amount of such information in order to improve the taxonomic identification of these fishes and understanding the evolutionary processes in this group. The members of the tribe Ancistrini have diploid numbers that vary from $2 \mathrm{n}=34$ in Ancistrus sp. from the Purus river to $2 \mathrm{n}=52$ in most of the other species karyotyped to date. Several sex chromosome systems have been identified, including simple and multiple systems, with either the male or the female as heterogametic sex. The numbers and localizations of the nucleolus organizer regions (NORs) are also rather variable; some species have simple NORs while others have multiple NORs (Artoni and Bertollo 2001, Alves et al. 2003, 2006, Souza et al. 2004, 2009, De Oliveira et al. 2006, 2007, 2008, 2009).

The genus Scobinancistrus Isbrücker et Nijssen, 1989 (Hypostominae, Ancistrini) comprises two species: S. pariolispos Isbrücker et Nijssen, 1989, which occurs in the Tapajós, Xingu and Tocantins Rivers, Brazil, and S. aureatus Burgess, 1994, which is endemic to the Xingu River (Fisch-Muller 2003, Camargo et al. 2004). They differ in that S. pariolispos has a fully evertible operculum, a final ray of the dorsal fin that extends as far as the adipose, and fins with no orange coloration (Camargo et al. 2012). No previous study has provided cytogenetic information for the two species of this genus.

In the present work, we obtained $S$. pariolispos and $S$. aureatus from the Xingu River and studied their karyotypes, in an effort to identify the processes involved in their karyotypic evolution and contribute new cytogenetic information for members of the tribe Ancistrini.

\section{Material and methods}

Samples of Scobinancistrus aureatus (seven females) and S. pariolispos (five males and two females) from the Xingu River, Brazil, were analyzed (Fig. 1). Metaphase chromosomes were obtained according to the method described by Bertollo et al. (1978) and analyzed by conventional staining (Giemsa), C-banding (Sumner 1972), Ag-NOR labeling (Howell and Black 1980), chromomycin $\mathrm{A}_{3}$ staining (Schweizer 1980), DAPI 

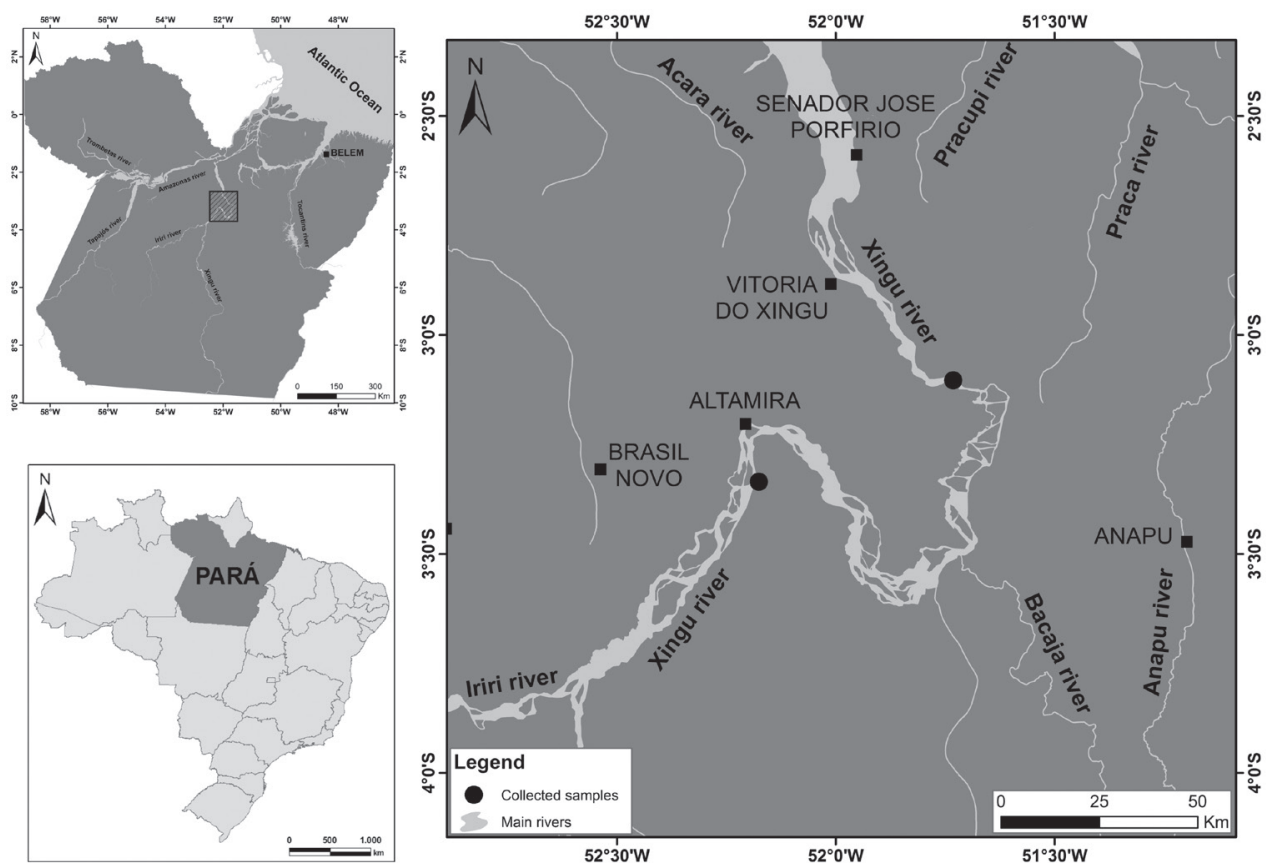

Figure I. Collection localities of the analyzed Scobinancistrus samples.

staining (Pieczarka et al. 2006), and fluorescence in situ hybridization (FISH) with $18 \mathrm{~S}$ ribosomal DNA (rDNA 18S) probes obtained from Prochilodus argenteus Agassiz, 1829 (Hatanaka and Galetti 2004) and human telomeric sequence probes (Oncor). The probes were labeled with biotin or digoxigenin by nick translation and detected with avidin-CY3 or anti-digoxigenin-FITC. The chromosomes were arranged according to the procedure described by Levan et al. (1964).

\section{Results}

The specimens of $S$. aureatus and $S$. pariolispos obtained from the Xingu River both had diploid numbers $2 \mathrm{n}=52$ chromosomes, but they differed in their karyotypic formulas (KFs), which were $22 \mathrm{~m}-20 \mathrm{sm}-10$ st and $24 \mathrm{~m}-18 \mathrm{sm}-10 \mathrm{st}$, respectively (Fig. 2A, B). Both males and females were analyzed for $S$. pariolispos, but no sex chromosomes were identified.

C-banding failed to identify constitutive heterochromatin $(\mathrm{CH})$ in the centromeric region of any chromosome in the studied species. In S. aureatus, large heterochromatic blocks were seen, as follows: in the proximal regions of the long arms of chromosome pairs 5, 6 and 18; in the proximal regions of the short arms of pair 13; throughout the short arms of pair 22; in the distal regions of the long arms of pairs 3 and 12; and in the distal regions of the short arms of pairs 12 and 18 (Fig. 2C). In $S$. pariolispos, conspicuous heterochromatic blocks were also identified throughout the 
A

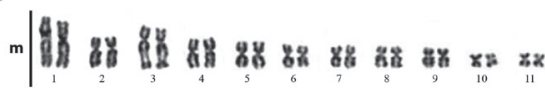

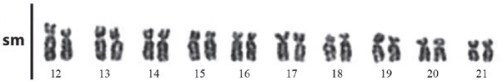

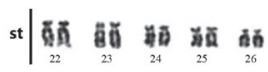

C

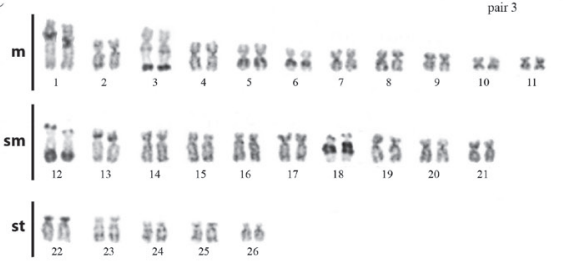

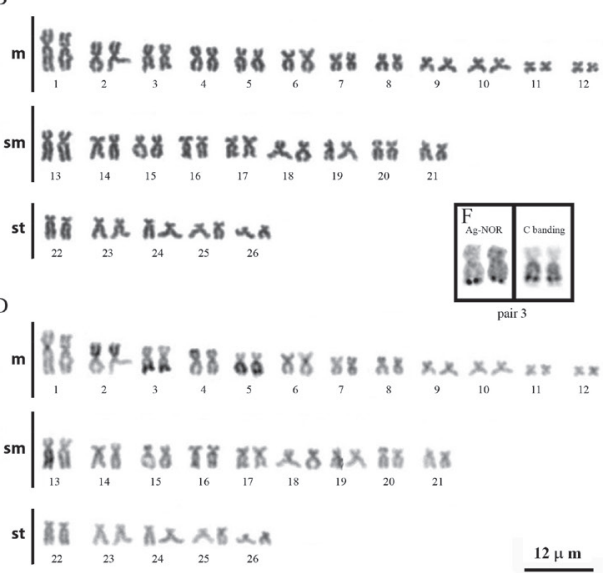

Figure 2. Karyotypic analyses of S.aureatus $(\mathbf{A}, \mathbf{B}$ and $\mathbf{E})$ and $S$. pariolispos $(\mathbf{B}, \mathbf{D}$ and $\mathbf{F})$ : conventional staining ( $\mathbf{A}$ and $\mathbf{B})$, C-banding $(\mathbf{C}$ and $\mathbf{D})$ and the NOR-bearing chromosome pair $(\mathbf{E}$ and $\mathbf{F})$. The scale bar refers to all images.

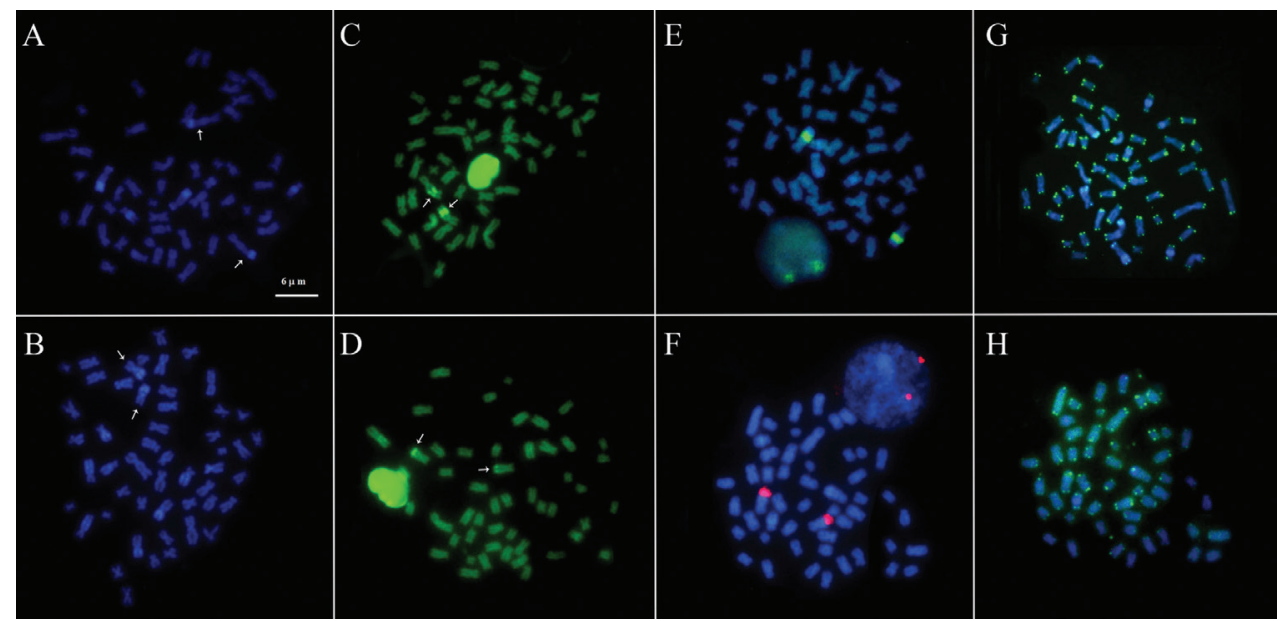

Figure 3. Further karyotypic analyses of $S$. aureatus $(\mathbf{A}, \mathbf{C}, \mathbf{E}$ and $\mathbf{G})$ and $S$. pariolispos $(\mathbf{B}, \mathbf{D}, \mathbf{F}$ and $\mathbf{H})$ : DAPI staining (A and $\mathbf{B}), \mathrm{CMA}_{3}$ staining $(\mathbf{C}$ and $\mathbf{D})$, FISH with $18 \mathrm{~S} \mathrm{rDNA}$ probes $(\mathbf{E}$ and $\mathbf{F})$ and FISH with telomeric sequence probes $(\mathbf{G}$ and $\mathbf{H})$. The scale bar refers to all images.

short arms of pair 2, in the distal regions of the long arms of pair 3, and throughout the long arms of pair 5 (Fig. 2D).

A NOR was identified on a single chromosome pair per species. In $S$. aureatus, the NOR was located in the interstitial region of the long arms of pair 3, flanked by $\mathrm{CH}$ (Fig. 2E). In S. pariolispos, the NOR was situated in the distal region of the long arms of pair 3, adjacent to a block of $\mathrm{CH}$ (Fig. 2F). The numbers and localizations of these regions were confirmed by FISH with $18 \mathrm{~S}$ ribosomal DNA probes (Fig. 3E, F). 
The DAPI fluorochrome labeled the heterochromatic regions (Fig. 3A, B), and $\mathrm{CMA}_{3}$ stained the NORs (Fig. 3C, D). In FISH using telomeric sequence probes (TTAGGG), the probes hybridized to the ends of all chromosomes, but no interstitial telomeric labeling was observed (Fig. 3G, H).

\section{Discussion}

Scobinancitrus aureatus and S. pariolispos from the Xingu River were found to have the same diploid number $(2 \mathrm{n}=52)$, but their KFs differed. This is consistent with most other species of tribe Ancistrini, which share $2 \mathrm{n}=52$ and differ in their KFs (Artoni and Bertollo 2001, Alves et al. 2003, 2006, Souza et al. 2004, 2009, De Oliveira et al. 2007). Chromosomal inversions, which are rearrangements that can modify the structure of chromosomes without altering their number, may explain how these species have the same diploid number but different KFs (Alves et al. 2003, De Oliveira et al. 2006). According to Artoni and Bertollo (2001) and Kavalco et al. (2005), 2n=54 probably corresponds to a basal condition for the Loricariidae. Therefore, the reduction to $2 \mathrm{n}=52$ in most of the Ancistrini species must be the result of a fusion event. The same type of rearrangement is believed to explain the reduction of the diploid number in several species of the genus Ancistrus Kner, 1854 (Alves et al. 2003, De Oliveira et al. 2009).

The NOR was found on the same chromosome pair in the two Scobinancistrus species studied here in this situation is shared by most members of the tribe Ancistrini (Artoni and Bertollo 2001, Alves et al. 2003, 2006, De Oliveira et al. 2007, Souza et al. 2004, 2009). The long arm of chromosome pair 3 was identified as the bearer of the NOR in both species; however, it was found in an interstitial, $\mathrm{CH}$-flanked region in $S$. aureatus, but in the distal region, adjacent to a $\mathrm{CH}$ block, in S. pariolispos. This organization indicates that the NOR-bearing chromosomes are not the same in $S$. aureatus and $S$. pariolispos, suggesting the occurrence of events that changed the position of the NOR within the karyotype (Fig. 4). The repetitive nature of the ribosomal DNA that constitutes the NOR and its association with $\mathrm{CH}$ (which consists mainly of satellite DNA and transposable elements; Dimitri et al. 2009) may facilitate transposition events that can move the NOR to another region of the genome (Gross et al. 2009, 2010). It is important to point out that the determination of chromosome pair numbers in these species is tentative, and therefore pair 3 of one species is not necessarily homologous to pair 3 of another species. However, we cannot exclude the possibility that these pairs are homologous and reflect the occurrence of a paracentric inversion involving the NOR and nearby HC. The NORs labeled positive for the fluorochrome, $\mathrm{CMA}_{3}$, but negative for DAPI, indicating that the ribosomal DNA is interspersed with repetitive GC-rich DNA, as has been frequently described in other fishes (Pendás et al. 1993).

The constitutive heterochromatin stained positive with DAPI, indicating that it is AT-rich. Its patterns differed between the two species, with large heterochromatic blocks in non-centromeric regions located predominantly in non-homologous chromo- 


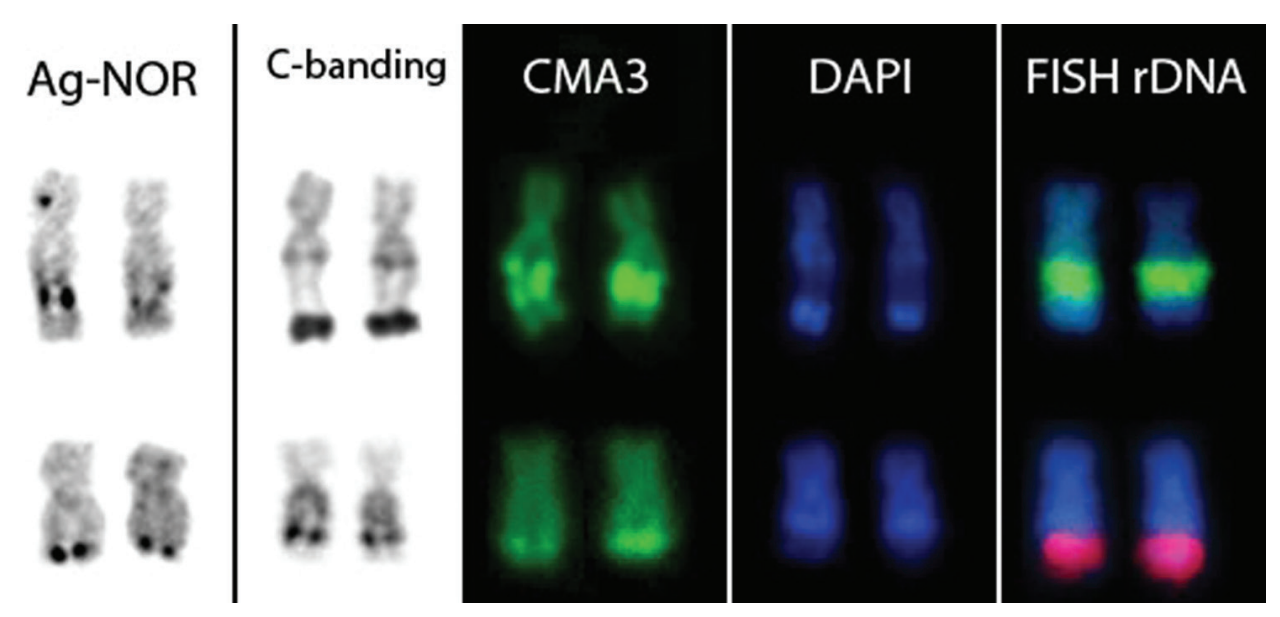

Figure 4. NOR-bearing chromosomes of $S$. aureatus (upper row) and $S$. pariolispos (lower row).

somes, indicating that processes related to the dynamics of repetitive DNA (e.g., transposition) may have been involved in the karyotypic differentiation of these two species.

Using information on karyotype macrostructures and $\mathrm{CH}$ and NOR distribution, Souza et al. (2009) identified chromosomes with possible homologies among species of genus Peckoltia Miranda Ribeiro, 1912, which belong to the tribe Ancistrini. However, using same criteria, we were unable to identify any homologies between the karyotypes of $S$. aureatus and $S$. pariolispos. This suggests that the studied karyotypes may have undergone both inversions (as noted above) and reciprocal translocation events, leading to greater genomic reorganization. Consistent with this, Nagamachi et al. (2010) used chromosome painting to demonstrate that the differences between two Gymnotus carapo Linnaeus, 1758 populations involved a greater number of chromosome rearrangements than previously assumed based on classical cytogenetic data (Milhomem et al. 2008).

In conclusion, the karyotypic differences found in the two Scobinancistrus species studied herein can be used in their taxonomic identification. Moreover, the sympatric occurrence of these species suggests that the identified karyotypic differences may have functioned as a mechanism of post-zygotic reproductive isolation during the speciation process.

\section{Acknowledgements}

We wish to thank Dr. Leandro Melo de Sousa (Federal University of Pará - Campus Altamira) for the taxonomic identification of the samples. Grants to support this research were provided by UFPA, CNPq, CAPES and by the project Vale-FAPESPA. The field collections were authorized by IBAMA (Brazilian Institute of Environment and Renewable Natural Resources). 


\section{References}

Alves AL, Oliveira C, Foresti F (2003) Karyotype variability in eight species of the subfamilies Loricariinae and Ancistrinae (Teleostei, Siluriformes, Loricariidae). Caryologia 56(1): 57-63. doi: 10.1080/00087114.2003.10589308

Alves AL, Oliveria C, Nirchio M, Granado A, Foresti F (2006) Karyotypic relatioships among the tribes of Hypostominae (Siluriformes: Loricariidae) with description of XO sex chromosome system in a Neotropical fish species. Genetica 128: 1-9. doi: 10.1007/s10709005-0715-1

Armbruster JW (2004) Phylogenetic relationships of the suckermouth armoured catfishes (Loricariidae) with emphasis on the Hypostominae and the Ancistrinae. Zoological Journal of the Linnean Society 141: 1-80. doi: 10.1111/j.1096-3642.2004.00109.x

Artoni RF, Bertollo LAC (2001) Trends in the karyotype evolution in the Loricariidae fish (Siluriformes). Hereditas 134: 201-210. doi: 10.1111/j.1601-5223.2001.00201.x

Bertollo LAC, Takashi CS, Moreira-Filho O (1978) Cytotaxonomic considerations on Hoplias lacerdae (Pisces, Erytrinidae). Brazilian Journal of Genetics 2: 103-120.

Camargo M, Giarrizzo T, Isaac V (2004) Review of the geographic distribution of fish fauna of the Xingu river basin, Brazil. Ecotropica 10: 123-147.

Camargo M, Gimênes-Junior H, Py-Daniel LR (2012) Acaris ornamentais do médiorio Xingu. Belém, $177 \mathrm{pp}$.

De Oliveira RR, Souza IL, Venere PC (2006) Karyotype description of three species of Loricariidae (Siluriformes) and occurrence of the ZZ/ZW sexual system in Hemiancistrus spilomma Cardoso \& Lucinda, 2003. Neotropical Ichthyology 4(1): 93-97. doi: 10.1590/ S1679-62252006000100010

De Oliveira RR, Feldberg E, Anjos MB, Zuanon J (2007) Karyotype characterization and ZZ/ZW heteromorphism in two species of the catfish genus Ancistrus Kner, 1854 (Siluriformes: Loricariidae) from the Amazon basin. Neotropical Ichthyology 5(3): 301-306. doi: 10.1590/S1679-62252007000300010

De Oliveira RR, Feldberg E, Anjos MB, Zuanon J (2008) Occurrence of multiple sexual chromosomes (XX/XY $Y_{2}$ and $Z_{1} Z_{1} Z_{2} Z_{2} / Z_{1} Z_{2} W_{1} W_{2}$ ) in catfishes of the genus Ancistrus (Siluriformes: Loricariidae) from the Amazon basin. Genetica 134(2): 243-249. doi: 10.1007/ s10709-007-9231-9

De Oliveira RR, Feldberg E, Anjos MB, Zuanon J (2009) Mechanisms of chromosomal evolution and its possible relation to natural history characteristics in Ancistrus catfishes (Siluriformes: Loricariidae). Journal of Fish Biology 75: 2209-2225. doi: 10.1111/j.10958649.2009.02450.x

Dimitri P, Caizzi R, Giordano E, Accardo MC, Lattanzi G, Biamonti G (2009) Constitutive heterochromatin: a surprising variety of expressed sequences. Chromosoma 118: 419-435. doi: 10.1007/s00412-009-0211-y

Fisch-Muller S (2003) Loricariidae-Ancistrinae (Armored catfishes). In: Reis RE, Kullander SO, Ferraris CJ Jr (Eds). Checklist of the Freshwater Fishes of South and Central America. Porto Alegre, 373-400. 
Gross MC, Schneider CH, Valente GT, Porto JIR, Martins C, Feldberg E (2009) Comparative cytogenetic analysis of the genus Symphysodon (Discus Fishes, Cichlidae): Chromosomal characteristics of retrotransposons and minor ribosomal DNA. Cytogenetic and Genome Research 127: 43-53. doi: 10.1159/000279443

Gross MC, Schneider CH, Valente GT, Martins C, Feldberg E (2010) Variability of 18 S rDNA locus among Symphysodon fishes: chromosomal rearrangements. Journal of Fish Biology 76: 1117-1127. doi: 10.1111/j.1095-8649.2010.02550.x

Hatanaka T, Galetti Jr PM (2004) Mapping of $18 \mathrm{~S}$ and 5 S ribosomal RNA genes in the fish Prochilodus argenteus Agassiz, 1829 (Characiformes, Prochilodontidae). Genetica 122: 239-244. doi: 10.1007/s10709-004-2039-y

Howell WM, Black DA (1980) Controlled silver-staining of nucleolus organizer regions with a protective colloidal developer: a 1-step method. Experientia 36: 1014-1015. doi: 10.1007/ BF01953855

Isbrücker IJH (1980) Classification and catalogue of the mailed Loricariidae (Pisces, Siluriformes). Verslagen en Technische Gegevens, Instituut voor Taxonomische Zoölogie, Universiteit van Amsterdam 22: 1-181.

Kavalco KF, Pazza R, Bertollo LAC, Moreira-Filho O (2005) Karyotypic diversity and evolution of Loricariidae (Pisces, Siluriformes). Heredity 94:180-186. doi: 10.1038/sj.hdy.6800595

Levan A, Fredga K, Sandberg AA (1964) Nomenclature for centromeric position on chromosomes. Hereditas 52: 201-220. doi: 10.1111/j.1601-5223.1964.tb01953.x

Milhomem SSR, Pieczarka JC, Crampton WGR, Silva DS, Souza ACP, Carvalho-Jr JR, Nagamachi CY (2008) Chromosomal evidence of a cryptic species in the Gymnotus carapo species-complex (Gymnotiformes-Gymnotidae). BMC Genetics 9: 75. doi: 10.1186/14712156-9-75

Nagamachi CY, Pieczarka JC, Milhomem SSR, O’Brien PCM, Souza ACP, Ferguson-Smith MA (2010) Multiple rearrangements in cryptic species of electric knifefish, Gymnotus carapo (Gymnotidae, Gymnotiformes) revealed by chromosome painting. BMC Genetics 11: 28. doi: 10.1186/1471-2156-11-28

Pendás AM, Morán P, Garcia-Vázquez E (1993) Ribosomal RNA genes are interspersed throughout a heterochromatin chromosome arm in Atlantic salmon. Cytogenetics and Cell Genetics 63: 128-130. doi: 10.1159/000133517

Pieczarka JC, Nagamachi CY, Souza ACP, Milhomem SSR, De Castro RR, Nascimento AL (2006) An adaptation to DAPI-banding to fishes chromosomes. Caryologia 59(1): 43-46.

Reis RE, Pereira EHL, Armbruster JW (2006) Delturinae, a new loricariid catfish subfamily (Teleostei, Siluriformes), with revisions of Delturus and Hemipsilichthys. Zoological Journal of the Linnean Society 147: 277-299. doi: 10.1111/j.1096-3642.2006.00229.x

Schweizer D (1980) Simultaneous fluorescent staining of R bands and specific heterochromatic regions (DA/DAPI bands) in human chromosomes. Cytogenetics and Cell Genetics 27: 190-193. doi: 10.1159/000131482

Souza ACP, Nascimento AL, Carvalho-Jr JR, Barros RMS, Feldberg E, Nagamachi CY, Pieczarka JC (2004) Karyotypic analysis of Baryancistrus aff. niveatus (Ancistrinae-Loricariidae) by C-banding, Ag-NOR, CMA 3 , DAPI and FISH. Caryologia 57(3): 219-223. doi: $10.1080 / 00087114.2004 .10589396$ 
Souza ACP, Nagamachi CY, Milhomem SSR, Feldberg E, Pieczarka JC (2009) Cytogenetics analysis in catfish species of the genus Peckoltia Miranda Ribeiro, 1912 (Teleostei: Siluriformes: Loricariidae). Comparative Cytogenetics 3(2): 103-109. doi: 10.3897/compcytogen.v3i2.17

Sumner AT (1972) A simple technique for demonstrating centromeric heterochromatin. Experimental Cell Research 75: 304-306. doi: 10.1016/0014-4827(72)90558-7 